Embryo research

SIR-I cannot claim to have read every word submitted to the Warnock Committee of Inquiry into Human Fertilisation and Embryology, of which I was a member, but I am reasonably sure that at least in our discussions the word "pre-embryo" was never used. Certainly we were all well aware that the human embryo for the first two weeks of its existence, and even more, bears no visual resemblance whatever to the later embryonic and fetal stages, but I can recall no efforts either within or from outside the committee to redefine the early stages as not an embryo. Within the past year, however, the word "pre-embryo" has been creeping in. For instance Maxine Clarke (Nature 319, 349; 1986) reports that nine research councils in Europe agree that research should be restricted to the "pre-embryo" and that the British Medical Research Council is supporting research to develop a test to identify healthy pre-embryos.

If research on embryos were an uncontentious matter, and if scientists were generally of the opinion that the new terminology helped their understanding, nobody would have many qualms at the name change. But those who are introducing "pre-embryo" into the vocabulary know full well that the research is indeed contentious and that fundamental issues have yet to be resolved. They complain, with justification, when embryos are described as "unborn children" in hostile parliamentary bills, but they are themselves manipulating words to polarize an ethical discussion.

The central issue is whether it is justifiable, once an egg has been fertilized, for anyone to perform experiments on the resulting embryo when those experiments are not in the best interests of that particular embryo. This is a complex and profound issue. The introduction of cosmetic words does not help.

Wester Ground,

David Davies

Chittlehamholt, Umberleigh, North Devon EX379NU, UK

David Davies was Editor of Nature from 1973 to 1980 .

\section{Price of star wars}

SIR-Joseph Hertzlinger (Nature 319, 8; 1986) has drawn attention to an aspect that I had overlooked in my letter (Nature 317,$470 ; 1985$ ) about some of the consequences of the US Strategic Defense Initiative (SDI). However, the plutonium scattered into the atmosphere by the nonnuclear explosion of a Soviet missile will not only increase the background alpharadiation by about 50 per cent; unlike naturally-occurring radon gas, it will be unevenly distributed in the troposphere and, as plutonium oxide, it will be in solid form. A litre of inhaled air containing $1 \mu \mathrm{g}$ of the oxide could be lethal; a litre of air free of the plutonium but with the average global proportion of radon gas would have less than one ten-millionth of the radioactivity of $1 \mu \mathrm{g}$ of plutonium and be virtually harmless.

Probably more important than the scattering of radioactive debris in the atmosphere, however, are the consequences of the arrival at ground level of guidancedamaged missiles and parts of exploded warheads containing plutonium-239. The rumpus caused by that part of the recent report of the Australian Royal Commission dealing with the British A-bomb crash tests at Maralinga related to the scattering of a few kilograms of plutonium over a test site in the Australian desert. In the SDI scenario, the amount of plutonium could be thousands of kilograms and the "test site" could be populated Europe

\section{Devana, Cardinal's Green,}

R.V. HaRRowelL

Horseheath, Cambridge CB1 6QX, UK

SIR-R.V. Harrowell (Nature 317, 470; 1985 ) raises an interesting question about a successful US defence system, but his conclusions may be misleading. Consider the more extreme case where $15,000 \mathrm{~kg}$ of plutonium-239 is uniformly dispersed throughout the $2 \times 10^{6} \mathrm{~km}^{2}$ of Europe (bounded by $5^{\circ} \mathrm{W}$ to $15^{\circ} \mathrm{E}$ longitude and $45^{\circ} \mathrm{N}$ to $55^{\circ} \mathrm{N}$ latitude). It is assumed that an operable ATBM (anti-theatre ballistic missile) defence system intercepts 100 per cent of the incoming warheads at very low altitudes. A simplified pathway to human intake will be used in which only the effects on the lungs due to inhalation of insoluble plutonium-239 are considered. The particle size of the plutonium-239 will be assumed to be about $1 \mu \mathrm{m}$ AMAD (activity median aerodynamic diameter). The deposition velocity is taken to be about $1 \mathrm{~cm} \mathrm{~s}^{-1}$, and the average breathing rate for humans is about $20 \mathrm{~m}^{3}$ per day. A rough estimate of the average mass of plutonium-239 that might be inhaled per person is

$$
\frac{(15,000 \mathrm{~kg})\left(20 \mathrm{~m}^{3} \mathrm{~d}^{-1}\right)}{\left(2 \times 10^{6} \mathrm{~km}^{2}\right)\left(1 \mathrm{~cm} \mathrm{~s}^{-1}\right)}=0.17 \mu \mathrm{g} .
$$

The committed dose per unit intake of inhaled plutonium-239 is $16 \mu \mathrm{Gy} \mathrm{Bq}$

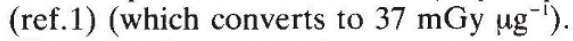
Thus, the dose commitment per person within the area of interest would be approximately $6 \mathrm{mGy}$. Since the ICRP (International Committee on Radiological Protection) limit for radiation workers is $25 \mathrm{mGy}$ (ref. 2), the doses that most people would receive are not lethal. There would certainly be an increase in the long-term effects (for example, lung cancers), but the short-term mortality rate would not be significantly changed.

The question of whether one dies quick- ly by nuclear annihilation or slowly by plutonium poisoning is not the central issue. The more realistic threats of future antiballistic missile (ABM) (and ATBM) defence systems deserve more attention.

The ABM Treaty of 1972 has recently raised a dilemma regarding the US Strategic Defense Initiative because it is only a bilateral measure and does not address the ATBM issues. This substantive deficiency must be addressed in the near future lest the heavens surely become the battleground of the twenty-first century.

BHUPENDRA JASANI Guy LeTtEer

\section{Stockholm International}

Peace Research Institute,

Pipers Väg 28,

S-171 73 Solna, Sweden

1. United Nations Scientific Committee on the Effects of Atomic Radiation (UNSCEAR), Ioniz ing Radiation: Sources and Biological Effects, 1982 Report to the General Assembly. Annex E. p. 239.

2. Recommendations of the International Commission on Radiological Protection, Annals of the ICRP ICRP Pub. 26. vol. 1, no. 3, January 1977.

\section{Women back to work}

SIR-In his article on career breaks ( $\mathrm{Na}$ ture 319, 522; 1986), Richard Pearson remarks that "many more women would return if it could be to part-time work". The academic world has been slow to recognize this important condition, but the situation is changing. For example, the Science and Engineering Research Council has given positive support for part-time appointments to its fellowships and grantfunded positions.

I have initiated a scheme of part-time fellowships for women wishing to return to academic research in science and engineering. The first group of fellowships has been funded by British Gas, British Telecom, GEC, the Leverhulme Trust, the Institute of Physics, ICI and BICC. Donations have been received from Rank Xerox and British Aerospace.

Over a quarter of a million pounds has so far been raised and the first seven fellows have been appointed. Ninety applications have been received; well over half of the applicants have PhDs and well over a third have industrial experience. Two essential features of the scheme are that the fellowships are part-time and retraining is available. The university departments involved have been most helpful.

It is hoped that this scheme will serve as a pilot project for the return of qualified women to industry. It is clear that returners should be offered flexible working patterns and that contact must be made through local press and radio.

Department of Physics,

D.F. JACKSON

University of Surrey.

Guildford, Surrey GU2 5XH, UK 